\title{
UTILIZAÇÃO DE ADITIVO EXPANSOR EM SISTEMA SOLO-ESTACA PARA AVALIAÇÃO DA INFLUÊNCIA DA ÁREA DE CONFINAMENTO
}

\author{
Use of expanding additive in a soil-pile system: an analysis of the confining \\ area influence
}

Guilherme Zorzi Andrighi'; Gilson Francisco Paz Soares²; Deise Trevizan Pelissaro ${ }^{3}$

${ }^{1}$ Diplomado em Engenharia Civil pela Universidade Regional do Alto Uruguai e das Missões - URI Erechim. E-mail: guilherme.andrighi@hotmail.com

${ }^{2}$ Doutor em Engenharia pela Universidade Federal do Rio Grande do Sul - UFRGS. Professor do curso de Engenharia Civil da Universidade Regional do Alto Uruguai e das Missões - URI Erechim. E-mail: gilsonfps@uricer.edu.br

${ }^{3}$ Mestre em Engenharia pela Universidade Federal do Rio de Janeiro - COPPE/UFRJ. Professora do curso de Engenharia Civil da Universidade Regional do Alto Uruguai e das Missões - URI Erechim. E-mail: deisetrevizan@uricer.edu.br

Data do recebimento: 20/01/2020 - Data do aceite: 09/04/2020

RESUMO: Estacas moldadas in loco são amplamente utilizadas na construção civil e são alvo constante de patologias envolvendo perda de resistência lateral durante o processo executivo. Decorrente disso, estudos para o melhoramento da capacidade de carga lateral destas estruturas se mostram relevantes. O presente trabalho buscou avaliar experimentalmente, por meio de protótipos de estacas, se a área de confinamento no entorno de uma estaca escavada, com a presença de um aditivo expansor de argamassa, pode interferir na capacidade de carga da estrutura por atrito lateral. Os resultados mostraram que, para as escalas adotadas, há uma pequena influência do solo confinado no entorno da estaca para variações de diâmetros avaliadas, o que pode significar, em tese, uma tendência de aumento da capacidade de carga das estacas com o aumento do diâmetro, de tal forma que essa melhoria possa ser maior em estacas de tamanho real.

Palavras-chave: Estacas. Confinamento. Aditivo Expansor de Argamassa. Capacidade de Carga. Atrito Lateral. 


\begin{abstract}
Cast in situ piles are widely used in construction and are constantly damaged by pathologies which results in the lateral strength loss during the executive process. As a result, studies to improve the lateral resistance capacity of these structures are relevant. The aim of this work was to evaluate, experimentally, through excavated pile prototypes, whether the confinement area around an in-situ molded pile, with the presence of a mortar expander additive may interfere with the load carrying capacity of the lateral friction structure. The results showed that, for the adopted scales, there is a small influence of the confined soil around the pile for variations of the evaluated diameters, which may mean in theory, a tendency to increase the load capacity of the piles with the increase in the diameter, in such a way that this improvement may be greater in real-size piles.
\end{abstract}

Keywords: Piles. Confinement. Mortar Expander Additive. Load Capacity. Lateral Friction.

\section{Introdução}

O crescimento populacional, associado à grande expansão no ramo da construção civil, faz com que seja necessário projetar e executar edificações que dispõem de carregamentos muito elevados. Essa demanda por edificações mais elaboradas e de grande porte exige um sistema estrutural e principalmente infraestrutura que resista a estes esforços.

Um projeto de fundações bem planejado e executado garante uma fundação bem dimensionada e a solidez da edificação. Porém, apesar da grande variedade dos sistemas, processos executivos e equipamentos, é indispensável o conhecimento das propriedades do maciço de solo, das particularidades do terreno e da obra a ser executada (PIAIA, 2017). As estacas, por sua vez, são exemplos de fundações profundas que suportam os carregamentos da superestrutura tanto por resistência de ponta quanto por atrito lateral.

O melhoramento do atrito lateral pode ser uma vantagem considerável quando se trata de fundações profundas de uma estrutura, podendo amenizar os problemas decorrentes das cargas oriundas das edificações, como também ajudar na prevenção de patologias já na fase inicial de execução. Nesse sentido, o uso de aditivos expansores de argamassa se mostra como uma possível alternativa para melhoramento do atrito lateral de estacas escavadas.

No intuito de avaliar uma possível melhoria na resistência por atrito lateral de estacas escavadas por meio do uso de aditivos expansores de argamassa, alguns trabalhos foram desenvolvidos utilizando uma metodologia experimental de laboratório que não apresenta normativas para execução. A metodologia consiste em simular uma estaca escavada em escala reduzida em um molde CBR onde o sistema solo-estaca fica confinado.

Dessa forma, este estudo tem a finalidade de analisar como a área de confinamento do solo pode influenciar na resistência por atrito lateral de um sistema solo-estaca moldado in loco com o uso de aditivo expansor de argamassa.

\section{Revisão da Literatura}

Segundo a NBR 6122 (ABNT, 2019), as fundações profundas são definidas como o 
elemento de fundação que transmite a carga ao terreno ou pela base (resistência de ponta), ou por sua superfície lateral (resistência de fuste), ou por uma combinação das duas, sendo sua ponta ou base apoiada em uma profundidade superior a oito vezes a sua menor dimensão em planta e no mínimo 3,0 m; quando não for atingido o limite de oito vezes, a denominação é justificada. Neste tipo de fundação incluem-se as estacas e os tubulões.

Com o avanço crescente de construções cada vez mais altas e com maior número de subsolos, há uma exigência por fundações que possuam uma maior capacidade de carga. Dessa forma, há um grande desenvolvimento de equipamentos tecnologicamente mais modernos, que permitem a execução de fundações mais robustas (profundidade e diâmetros maiores), possibilitando maiores opções de escolhas (GOTLIEB, 2015). Nesse contexto as estacas moldadas in loco se destacam pela possibilidade de atingir maiores profundidades sem emendas e por apresentar maiores diâmetros. Em contrapartida, as estacas escavadas apresentam a desvantagem de apresentar patologias associadas a perda de resistência lateral durante o processo de execução. Estas estacas possuem capacidade de carga provenientes da resistência de ponta e atrito lateral, em que, para Décourt (1998), a mobilização do atrito lateral é influenciada, principalmente, pelo comprimento e forma da estaca.

Décourt (1998) afirma ainda que o atrito lateral que se desenvolve entre solo e estaca pode ocorrer a partir de pequenas deformações, diferenciando-se da reação de ponta que necessita de deformações muito maiores para que se mobilize.

Além disso, a implantação de estacas em solos adensáveis pode gerar o chamado atrito negativo, no qual o recalque da estaca é superado pelo recalque de adensamento. Com isso, a camada adensável passa a propiciar o aumento da solicitação vertical na estaca, de cima para baixo, em vez de contribuir com o atrito lateral positivo, que é o que resiste aos carregamentos (AOKI; CINTRA, 2010).

Dada a relativa falta de conhecimentos sobre qualidade e grandeza dos efeitos da interação solo-estrutura nas edificações, verifica-se a necessidade de pesquisas que abordem tal assunto. Elas são importantes para dar o devido embasamento teórico aos profissionais de engenharia, permitindo que seja feito um dimensionamento estrutural mais adequado, e alertá-los para este problema tão comumente negligenciado (HOLANDA, 1998).

Uma das técnicas para o melhoramento de um sistema solo-estrutura de fundações que é utilizada atualmente em solo arenosos é a por meio de estacas de compactação. Segundo Soares (2002), esse processo, conhecido nos meios científicos como "vibro-deslocamento", consegue, por meio da cravação de estacas de compactação, densificar as camadas de areia próximas à superfície, aumentando assim a resistência à penetração das mesmas e, por consequência, a sua resistência à compressão e ao cisalhamento.

Outra técnica de que se faz uso são as colunas de cimento na forma DSM (Deep Soil Mixing). Essa técnica consiste na melhoria do solo por meio de uma mistura in situ do solo com diferentes aglutinantes estabilizadores que reagem com o solo e a água presente no solo. Tanto a cal quanto a combinação de cal com cimento podem ser utilizadas no tratamento pela metodologia DSM (MORETTI, 2012).

Recentemente, o uso de aditivos expansores de argamassa vem sendo avaliado como uma possível alternativa para o melhoramento do sistema solo-estrutura. De acordo com Yazigi (1999), os aditivos, quando adicionados em pequenas quantidades, são produtos que podem modificar algumas das propriedades de concretos onde se utiliza cimento 
Portland, com a função de melhor adequar essas propriedades a determinadas condições. Segundo o autor, o aditivo expansor de argamassa é aquele que, a partir da formação de gases, provoca a expansão do concreto. $\mathrm{O}$ alumínio é um expansor muito comum, em pó muito fino, que reage com o aluminato tricálcico de cimento e causa o desprendimento de hidrogênio. Esse tipo de aditivo é utilizado quando se deseja uma expansão do concreto no interior de cavidades. Os teores a serem usados estão entre $1 \%$ e $2 \%$.

$\mathrm{O}$ aditivo expansor de argamassas a ser utilizado é um produto com consistência de pó, que tem como ação principal a expansão e, posteriormente, a plasticidade. A expansão que o aditivo gera compensa o assentamento natural e retração plástica dos materiais cimentícios, o que promove coesão e estabilidade ao material empregado (VEDACIT, 2020).

Natalli (2017) relata que esses aditivos apresentam melhora na trabalhabilidade da argamassa, pois são os responsáveis por incorporarem bolhas de ar na matriz cimentícia, melhorando sua fluidez de mistura. Com suas particularidades, eles também evitam o encolhimento do núcleo de concreto empregado, fortalecendo o vínculo na interface dos materiais constituintes. No entanto, a resistência da estrutura não apresenta melhoria com a adição desse produto.

Lorenzon (2016) abordou, em seu trabalho, uma reanálise do estudo de Biondo (2007), objetivando avaliar a melhoria do atrito lateral por meio do uso de aditivo ao concreto, modelando uma estaca em tamanho reduzido e levando-a à ruptura. $\mathrm{O}$ autor constatou que no trabalho de Biondo (2007) os moldes foram confeccionados abaixo da umidade ótima, possibilitando uma análise mais crítica dos resultados e a constatação da melhoria do atrito lateral da estaca.

Piaia (2017), em seu estudo, verificou e comparou, a partir do uso de aditivo expan- sor de argamassa de um modelo reduzido de estaca de fundação, o comportamento de solos de diferentes granulometrias de partículas sólidas, analisando a resistência por atrito lateral do solo com a estaca. A autora obteve um atrito lateral de $108,895 \mathrm{kPa}$ para o solo Argila-Arenosa e 63,32 kPa para o solo Areia-Argilosa, representando um aumento de $6,44 \%$ e $20,75 \%$, respectivamente, em relação aos mesmos solos sem a utilização do aditivo. Os resultados mostraram que a granulometria do solo exerce influência no atrito lateral de estacas com uso de aditivo expansor e que houve a melhora do sistema solo-estaca, porém os valores de atrito lateral encontrados são baixos.

Apesar dos estudos citados apresentarem resultados favoráveis e promissores em relação à utilização de aditivos expansores de argamassa para o melhoramento da interação entre o solo e a estrutura, os estudos são ainda recentes e existem algumas lacunas, principalmente em relação à metodologia experimental utilizada, que são abordadas neste trabalho.

\section{Metodologia}

As amostras de solo foram coletadas na cidade de Itatiba do Sul, RS, e, posteriormente, submetidas a um processo de secagem natural e verificação da umidade higroscópica, conforme recomendações da NBR 6457 (2016). Para a confecção da argamassa foram utilizados cimento CP V, areia de granulometria média e aditivo expansor de argamassa na proporção de $1 \%$ em relação à massa de cimento. $O$ traço da argamassa de 1:2,5 foi obtido a partir dos trabalhos de Lorenzon (2016) e Piaia (2017), por apresentar melhor resistência à compressão.

A etapa de caracterização do solo consistiu nos ensaios de análise granulométrica, limites de liquidez e plasticidade, densidade 
real do solo e compactação seguindo as prescrições normativas dos mesmos.

Para a confecção dos protótipos das estacas adotou-se como variáveis controláveis o diâmetro da estaca e a utilização ou não de aditivos na composição da argamassa. Os corpos de prova foram moldados em cilindro CBR grande na umidade ótima, utilizando energia intermediária. Posteriormente, foi realizada uma perfuração central nos $\mathrm{CPs}$, a qual foi preenchida com argamassa conforme a Figura 1.

Figura 1 - a) Preenchimento com argamassa b) Perfuração do corpo de prova

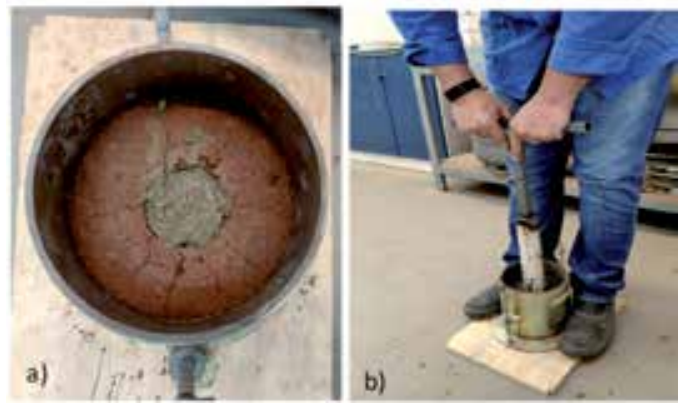

Após sete dias de cura, utilizando a prensa CBR, os CPs foram submetidos a carregamentos até atingir a resistência da argamassa. Para esse processo foi acoplada uma placa com uma perfuração central de mesmo diâmetro que as estacas, de modo que a base dos protótipos das estacas estivesse livre em contato com nada e as mesmas pudessem se deslocar livremente. Dessa forma, a resistência obtida se deve apenas pela resistência por atrito lateral. Na Figura 2 é apresentado o deslocamento de uma estaca após ser submetida ao carregamento.

Figura 2 - Deslocamento da estaca após o carregamento

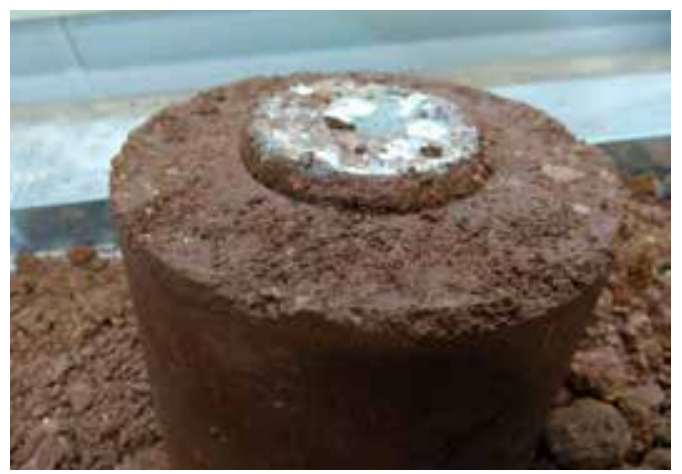

Figura 3 - Curva granulométrica do solo

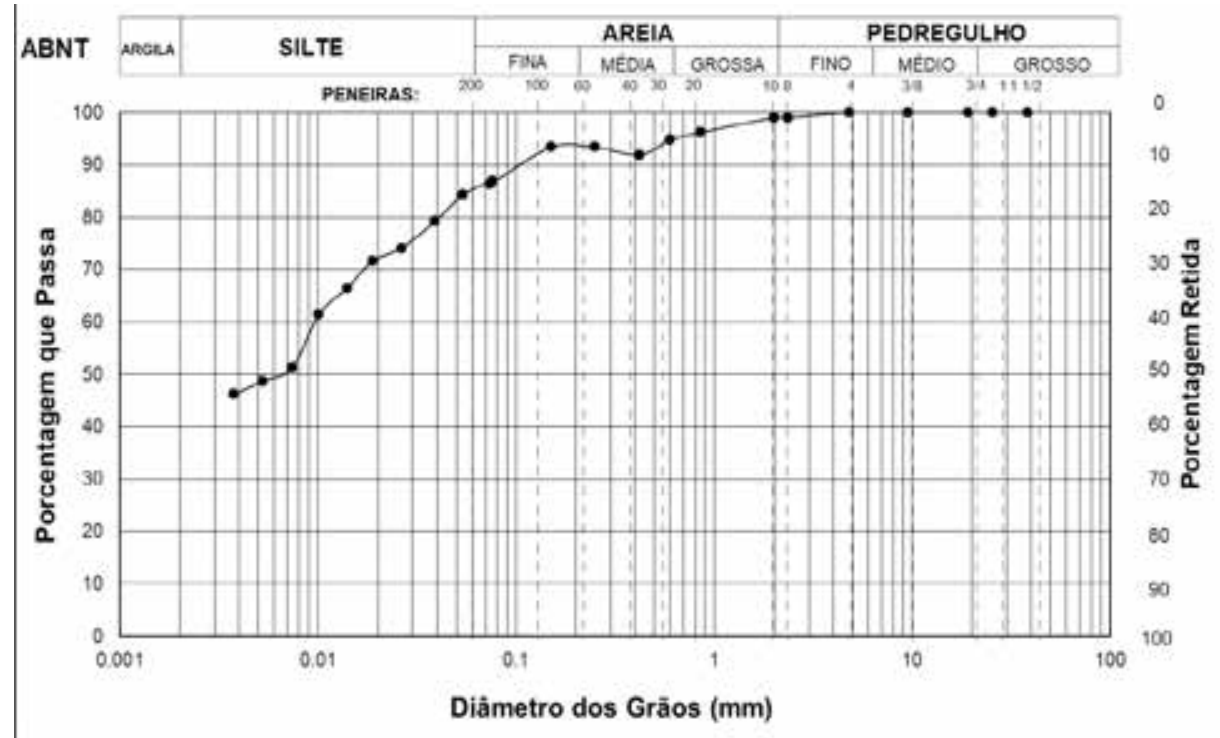




\section{Resultados e Discussão}

A análise granulométrica apresentou $85 \%$ de silte, $13 \%$ de areia e $1 \%$ de pedregulho, conforme a Figura 3, classificando-o como um solo siltoso-arenoso.

Os resultados dos limites de Atterberg apresentaram limite de liquidez de 49,70\%, limite de plasticidade de $24,96 \%$ e índice de plasticidade de $24,76 \%$, o que classifica o solo como de alta plasticidade.

A partir do ensaio de compactação foi possível estabelecer uma massa específica aparente seca máxima do solo de $1,775 \mathrm{~g} / \mathrm{cm}^{3}$ e umidade ótima de 18,3\%, conforme Figura 4 , que corresponde à umidade em que os CPs foram moldados.

Figura 4 - Curva de compactação

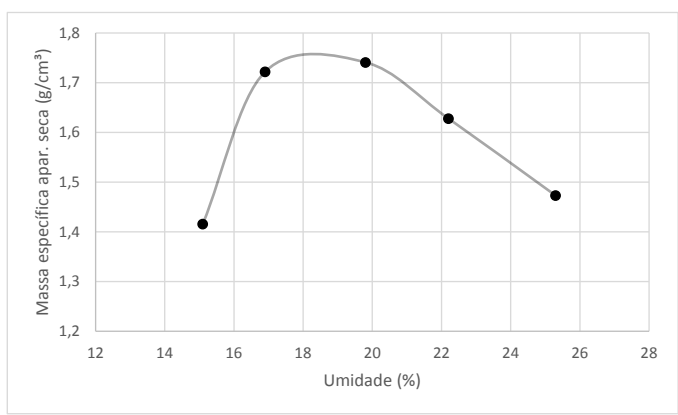

Os ensaios de compressão foram divididos em dois grupos a fim de avaliar as variáveis isoladamente. Inicialmente foram moldados
6 corpos de prova, dos quais 3 apresentavam aditivo e os demais não. As cargas de ruptura encontradas para a argamassa estão dispostas na Tabela I.

A partir dos resultados apresentados na Tabela I, observa-se que o acréscimo do aditivo na argamassa não apresentou uma melhora na resistência do sistema, o que condiz com a hipótese de Lorenzon (2016), na qual o aumento de resistência à estrutura não é atribuído à presença do aditivo expansor de argamassa.

Embora não tenha sido utilizado o mesmo solo, os valores médios encontrados para a resistência axial à compressão são semelhantes aos encontrados por Piaia (2017) e Lorenzon (2016), assegurando a confiabilidade dos ensaios e do processo de execução dos mesmos, uma vez que não existem normativas para a confecção dos protótipos.

O segundo grupo de corpos de prova consistiu em relacionar o deslocamento das estacas com a área de confinamento do sistema solo-estaca. Foram moldados $3 \mathrm{CPs}$ para cada diâmetro analisado $(6 \mathrm{~cm}$ e $8 \mathrm{~cm})$. A Figura 5 apresenta os valores médios dos deslocamentos obtidos nos ensaios para os corpos de prova sem e com a presença de aditivo.

Os valores de deslocamento médio para as estacas aditivadas apresentaram resultados inferiores em comparação com as mesmas sem a presença de aditivo, o que mostra um possível aumento na resistência por atrito lateral, proporcionada pela expansão do aditivo

Tabela I - Cargas de ruptura da argamassa

\begin{tabular}{cccc}
\hline Corpos de prova (CPs) & Força admissível (kN) & Presença de aditivo & Média (kN) \\
\hline CP 1 & 36,31 & Não & \\
CP 2 & 36,16 & Não & 36,74 \\
CP 3 & 37,76 & Não & \\
CP 4 & 36,31 & Sim & \\
CP 5 & 36,16 & Sim & 36,74 \\
CP 6 & 37,76 & Sim & \\
\hline
\end{tabular}


incorporado na argamassa e, consequentemente, o preenchimento dos vazios do solo.

Figura 5 - Deslocamento médio das estacas

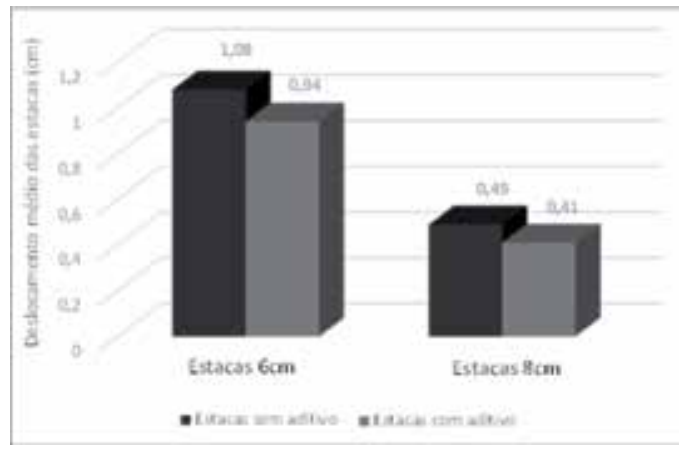

A avaliação da área de confinamento dos protótipos pode ser observada a partir da Figura 6, onde, ao aumentar o diâmetro do protótipo, ocorre uma redução na área de confinamento do sistema. Verifica-se que para as estacas de $8 \mathrm{~cm}$ houve uma redução de $16,33 \%$ no deslocamento ao adicionar aditivo, enquanto, para as estacas de $6 \mathrm{~cm}$, essa mesma alteração resultou em uma redução de $12,56 \%$.

Figura 6 - Percentual de deslocamento das estacas

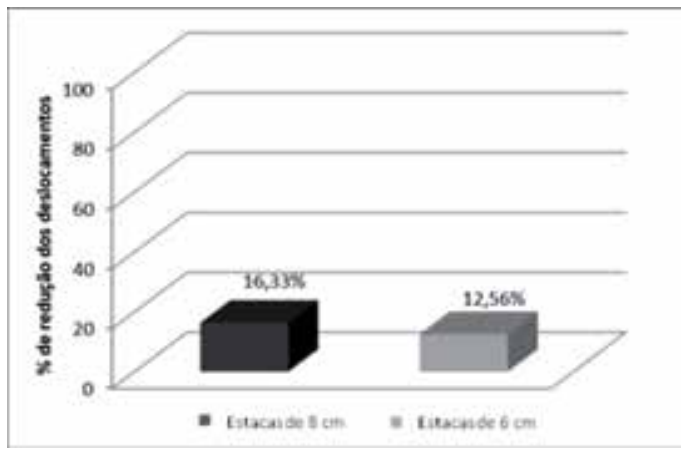

Embora para os dois diâmetros avaliados a redução no deslocamento tenha sido de apenas $4 \%$, podendo ser considerada desprezível, quando avaliados individualmente os percentuais de $16,33 \%$ e $12,56 \%$ se mos- tram significativos e sugerem uma possível influência do confinamento do solo.

\section{Conclusão}

O presente trabalho teve como objetivo analisar a influência da área de confinamento em um protótipo de estaca escavada com a presença de um aditivo expansor de argamassa, a fim de observar se execução de protótipos de estacas moldadas em um cilindro CBR pode ser aplicada a casos práticos em que o solo não se encontra confinado.

Em uma primeira análise, nos CPs moldados separadamente do sistema solo-estaca, pode-se concluir que o acréscimo de aditivo, por si só, não altera a resistência da argamassa. No entanto, ao incorporar o aditivo no sistema solo-estaca observou-se uma redução no deslocamento das estacas e, consequentemente, um aumento na resistência por atrito lateral. Esse acréscimo de resistência é, portanto, atribuído à incorporação do aditivo expansor nos vazios do solo, proporcionando uma melhor aderência do sistema.

Foi possível verificar que o aumento do diâmetro das estacas de $6 \mathrm{~cm}$ para $8 \mathrm{~cm}$, diminuindo a área de confinamento do sistema solo-estrutura, resultou na redução de deslocamento das estacas. Isso confirma o estudo de Lima (2015), em que estacas com maiores diâmetros se comportam melhor quando se trata de deslocamentos, já que, quanto maior for o diâmetro, maior será sua rigidez.

Conclui-se então que, para as escalas adotadas neste trabalho, há uma influência significativa do solo confinado no entorno da estaca para variações de diâmetros adotadas. No entanto, sugere-se reproduzir esta metodologia de ensaio para outros diâmetros, a fim de que se possa validar o uso dos resultados em laboratório em grande escala. 


\section{REFERÊNCIAS}

Associação Brasileira de Normas Técnicas (2016). NBR 6547 - Preparação de amostras de solo para ensaio normal de compactação e caracterização, Procedimento. Rio de Janeiro.

Associação Brasileira de Normas Técnicas (2019). NBR 6122 - Projeto e execução de fundações. Rio de Janeiro.

AOKI, N.; CINTRA, J. C. A. Fundações: projeto geotécnico. São Paulo (SP): Oficina e Textos, 2010.

BIONDO, M. Verificação da otimização do sistema solo-estaca com o uso de concreto aditivado com expansor de argamassa. 2007. Monografia (Graduação em Engenharia Civil) - Universidade Comunitária da Região de Chapecó, Chapecó, SC, 2007.

DÉCOURT, L. (1998). Análise e Execução de Estacas Profundas. In W. HACHICH et al. (eds.), Fundações: Teoria e Prática, 2 ed., Editora Pini, São Paulo, 265-302 p.

GOTLIEB, I. Fundações Profundas. Revista Construção Mercado - PINI, 2015. Disponível em: http://construcaomercado.pini.com.br/negocios-incorporacao construcao/163/artigo338059- 2.aspx. Acesso em: 02 jan. 2020.

HOLANDA, O. G. Interação solo-estrutura para edifícios de concreto armado sobre fundações diretas. 1998. Dissertação (Mestrado em Engenharia de Estruturas) - Escola de Engenharia de São Carlos - Universidade de São Paulo, São Paulo, SP, 1998.

LORENZON, T. Reanálise da interação do solo-estaca moldada "in loco" com o uso de aditivo expansor de argamassa. 2016. Monografia (Graduação em Engenharia Civil) - Universidade Comunitária da Região de Chapecó, Chapecó, SC, 2016.

MORETTI, G. V. Comportamento à compressão de solo estabilizado com cimento utilizado em colunas de deep soil mixing. 2012. Dissertação (Mestrado em Engenharia Agrícola) - Universidade Estadual de Campinas, Campinas, SP, 2012.

NATALLI, J. F. Desempenho do concreto leve em seções mistas. 2017. Dissertação (Mestrado em Engenharia Civil) - Universidade Federal de Ouro Preto, Minas Gerais, MG, 2017.

PIAIA, N. Análise da otimização do sistema solo-estaca com o uso de concreto aditivado com expansor de argamassa em diferentes solos. 2017. Monografia (Graduação em Engenharia Civil) Universidade Comunitária da Região de Chapecó, Chapecó, SC, 2017.

SOARES, W. C. Estacas de Compactação para melhoria de solo. 2002. Dissertação (Mestrado em Geotecnia) - Universidade de São Paulo, São Paulo, SP, 2002.

VEDACIT, impermeabilizantes. Aditivo expansor de argamassa. 2017. Disponível em: https://www. vedacit.com.br/produtos-e-solucoes/aditivos/expansor. Acesso em: 21 abr.2020.

YAZIGI, W. A técnica de edificar. 2. ed. São Paulo (SP). Pini: SINDUSCON, 1999. 